\title{
Commentary: Predicting patients at risk for complications after thoracic surgery-Application in the era of enhanced recovery
}

\author{
Mara B. Antonoff, MD
}

\author{
From the University of Texas MD Anderson Cancer Center, Houston, Tex. \\ Disclosures: Author has nothing to disclose with regard to commercial support. \\ Received for publication Feb 1, 2019; accepted for publication Feb 1, 2019; available ahead of print March 20, \\ 2019. \\ Address for reprints: Mara B. Antonoff, MD, 1400 Pressler St, Unit 1489, Houston, TX 77030 (E-mail: \\ mbantonoff@mdanderson.org). \\ J Thorac Cardiovasc Surg 2019;157:2502-3 \\ $0022-5223 / \$ 36.00$ \\ Copyright (c) 2019 by The American Association for Thoracic Surgery \\ https://doi.org/10.1016/j.jtcvs.2019.02.007
}

For patients undergoing lung and esophageal resection, postoperative atrial fibrillation represents a fairly common event, affecting 1 in every 6 individuals. ${ }^{1}$ This potentially preventable adverse outcome has a number of negative implications, as it is associated with acute hemodynamic instability, thromboembolic complications, and increased mortality. ${ }^{2,3}$ A number of investigators have sought to identify clinical predictors of atrial fibrillation, with reasonable success in using preoperative echocardiographic findings. ${ }^{4}$ However, echocardiography can be resource intense, and a simpler means of reliably identifying patients at risk is of particular interest.

Brain natriuretic peptide (BNP) level is easily assessed with a straightforward laboratory blood draw, and previous work by Amar and colleagues ${ }^{5}$ has shown utility in its application as a predictor of atrial fibrillation after general thoracic surgical procedures. Building upon their earlier investigations, Amar and colleagues ${ }^{6}$ have put forth further research in this area, describing in this issue of the Journal their development of a novel clinical prediction model for postoperative atrial fibrillation which includes BNP as well as several other clinical variables.

In this well-executed study, Amar and colleagues ${ }^{6}$ reviewed the charts of patients who underwent routine BNP measurement within the month prior to lung or esophageal surgery, among whom $20 \%$ ultimately developed postoperative atrial fibrillation. After construction of a prediction model, a nomogram was generated for risk estimation, including age, body mass index, history of atrial fibrillation, extent of surgical resection, and preoperative BNP level. Importantly, Amar and colleagues ${ }^{6}$ found that the model that included BNP was more accurate than the model without BNP, justifying the inclusion of this biomarker.

Consequent to their findings, Amar and colleagues ${ }^{6}$ have suggested that all patients undergoing preoperative evaluation for noncardiac thoracic surgery ought to have BNP measured and their risk of atrial fibrillation estimated from

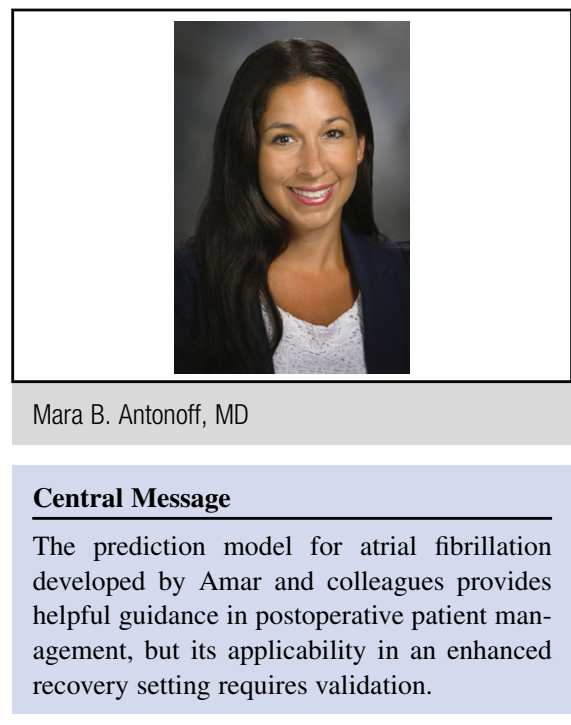

See Article page 2493.

the nomogram. Moreover, Amar and colleagues ${ }^{6}$ have implicated that patients at higher calculated risk for atrial fibrillation development should be considered for potential antiarrhythmic prophylaxis, on the basis of previously published guidelines and studies. ${ }^{2,7}$ Certainly, efforts to prevent atrial fibrillation in high-risk individuals may be beneficial to our patients, potentially avoiding negative adverse events related to the arrhythmia as well as the typical prolongation of hospital stay that tends to accompany its development. ${ }^{2}$ The proposed nomogram is easy to use, straightforward, and, following external validation, could be considered for generalizable applicability to a large population of patients undergoing thoracic surgical resections.

Consistent with previous reports, patients in this study developed atrial fibrillation after a median of 2 days, with a range of 0 to 6 days. ${ }^{6}$ This timing is of particular interest, given the heightened emphasis in our field on enhanced recovery pathways after thoracic surgery, many of which have led to expedited hospital discharge. ${ }^{8,9}$ While Amar and colleagues ${ }^{6}$ have made an excellent recommendation that patients at high risk for atrial fibrillation may need prophylaxis, one must also consider that patients treated under enhanced recovery protocols may potentially be discharged before their development of atrial fibrillation. Thus, another 
important use for this nomogram may be in alerting practitioners of patients at risk to help guide decisions regarding appropriateness of early discharge. However, somewhat complicating the picture, evidence from Van Haren and associates $^{9}$ has shown a reduction in postoperative cardiac complications (including atrial fibrillation) from $18 \%$ to $12 \%$ following the implementation of an enhanced recovery program. Therefore, while nomograms such as that developed by Amar and colleagues ${ }^{6}$ may prove useful in avoiding early discharge of patients at high risk for atrial fibrillation, it is not clear that the probability of atrial fibrillation is equivalent among patients treated under enhanced recovery pathways. In order to clarify the appropriate application of this nomogram in the present health care environment, it will be vitally important to perform external validation of the tool for patient populations treated under enhanced recovery protocols.

\section{References}

1. Passman RS, Gingold DS, Amar D, Lloyd-Jones D, Bennett CL, Zhang H, et al. Prediction rule for atrial fibrillation after major noncardiac thoracic surgery. Ann Thorac Surg. 2005;79:1698-703.
2. Frendl G, Sodickson AC, Chung MK, Waldo AL, Gersh BJ, Tisdale JE et al; American Association for Thoracic Surgery. 2014 AATS guidelines for the prevention and management of perioperative atrial fibrillation and flutter for thoracic surgical procedures. J Thorac Cardiovasc Surg. 2014; 148:e153-93.

3. Onaitis M, D'Amico T, Zhao Y, O'Brien S, Harpole D. Risk factors for atrial fibrillation after lung cancer surgery: analysis of the Society of Thoracic Surgeons general thoracic surgery database. Ann Thorac Surg. 2010;90:368-74.

4. Nojiri T, Maeda H, Takeuchi Y, Funakoshi Y, Maekura R, Yamamoto K, et al. Predictive value of preoperative tissue Doppler echocardiographic analysis for postoperative atrial fibrillation after pulmonary resection for lung cancer. $J$ Thorac Cardiovasc Surg. 2010;140:764-8.

5. Amar D, Zhang H, Shi W, Downey RJ, Bains MS, Park BJ, et al. Brain natriuretic peptide and risk of atrial fibrillation after thoracic surgery. J Thorac Cardiovasc Surg. 2012;144:1249-53.

6. Amar D, Zhang H, Tan KS, Piening B, Rusch VW, Jones DR. A brain natriuretic peptide-based prediction model for atrial fibrillation after thoracic surgery: development and internal validation. J Thorac Cardiovasc Surg. 2019;157:2493-9.e1.

7. Cardinale D, Sandri MT, Colombo A, Salvatici M, Tedeschi I, Bacchiani G, et al. Prevention of atrial fibrillation in high-risk patients undergoing lung cancer surgery: the PRESAGE trial. Ann Surg. 2016;264:244-51.

8. Martin LW, Sarosiek BM, Harrison MA, Hedrick T, Isbell JM, Krupnick AS, et al Implementing a thoracic enhanced recovery program: lessons learned in the first year. Ann Thorac Surg. 2018;105:1597-604.

9. Van Haren RM, Mehran RJ, Mena GE, Correa AM, Antonoff MB, Baker CM, et al. Enhanced recovery decreases pulmonary and cardiac complications after thoracotomy for lung cancer. Ann Thorac Surg. 2018;106:272-9. 